\title{
Seasonality and extent of extratropical TST derived from in-situ CO measurements during SPURT
}

\author{
P. Hoor ${ }^{1,2}$, C. Gurk ${ }^{2}$, D. Brunner ${ }^{1}$, M.I. Hegglin ${ }^{1}$, H. Wernli ${ }^{1,3}$, and H. Fischer ${ }^{2}$ \\ ${ }^{1}$ Institute for Atmospheric and Climate Science, Swiss Federal Institute of Technology, Zürich, Switzerland \\ ${ }^{2}$ Max Planck Institute for Chemistry, Air Chemistry, Mainz, Germany \\ ${ }^{3}$ Institute for Atmospheric Physics, University of Mainz, Germany
}

Received: 26 January 2004 - Published in Atmos. Chem. Phys. Discuss.: 16 March 2004

Revised: 24 August 2004 - Accepted: 24 August 2004 - Published: 27 August 2004

\begin{abstract}
We present airborne in-situ trace gas measurements which were performed on eight campaigns between November 2001 and July 2003 during the SPURT-project (SPURenstofftransport in der Tropopausenregion, trace gas transport in the tropopause region). The measurements on a quasi regular basis allowed an overview of the seasonal variations of the trace gas distribution in the tropopause region over Europe from $35^{\circ}-75^{\circ} \mathrm{N}$ to investigate the influence of transport and mixing across the extratropical tropopause on the lowermost stratosphere.
\end{abstract}

From the correlation of $\mathrm{CO}$ and $\mathrm{O}_{3}$ irreversible mixing of tropospheric air into the lowermost stratosphere is identified. The $\mathrm{CO}$ distribution indicates that transport and subsequent mixing of tropospheric air across the extratropical tropopause predominantly affects a layer, which closely follows the shape of the local tropopause. In addition, the seasonal cycle of $\mathrm{CO}_{2}$ illustrates the strong coupling of that layer to the extratropical troposphere. Both, horizontal gradients of $\mathrm{CO}$ on isentropes as well as the $\mathrm{CO}-\mathrm{O}_{3}$-distribution in the lowermost stratosphere reveal that the influence of quasihorizontal transport and subsequent mixing weakens with distance from the local tropopause. The mixing layer extends to about $25 \mathrm{~K}$ in potential temperature above the local tropopause exhibiting only a weak seasonality.

However, at large distances from the tropopause a significant influence of tropospheric air is still evident. The relation between $\mathrm{N}_{2} \mathrm{O}$ and $\mathrm{CO}_{2}$ indicates that a significant contribution of air originating from the tropical tropopause contributes to the background air in the extratropical lowermost stratosphere.

\section{Introduction}

Mixing of tropospheric air across the extratropical tropopause plays an important role for the trace gas composition in the lowermost stratosphere affecting chemistry and radiative transfer in the UT/LS region at mid and high latitudes. Tropospheric pollutants like volatile organic compounds (VOC's) and reactive nitrogen affect local chemistry in the lowermost stratosphere, thereby acting in particular on the budgets of $\mathrm{HO}_{\mathrm{x}}$ and $\mathrm{O}_{3}$. Photochemical production of $\mathrm{O}_{3}$ (Lacis et al., 1990) and mixing of infrared active species originating from the troposphere have direct impact on the radiation budget and therefore on the temperature distribution in the lowermost stratosphere. In particular trends of $\mathrm{O}_{3}$ in that region are subject to large uncertainties due to the high variability of the underlying photochemical and dynamical processes (WMO, 2003). Therefore, a detailed understanding of extratropical cross tropopause transport and its effect on the trace gas composition is essential to understand the processes controlling photochemistry in the lowermost stratosphere.

It is well known that tropospheric air enters the stratosphere predominantly in the tropics where air is lifted upwards and polewards on timescales of several years as part of the Brewer-Dobson circulation (Holton et al., 1995). Diabatic downward motion occurs at mid- and high latitudes exhibiting a seasonal cycle. Downward flux through the $\Theta=380 \mathrm{~K}$ surface maximizes during winter (Appenzeller et al., 1996) contributing to the trace gas composition of the lowermost stratosphere. According to Hoskins (1991) the lowermost stratosphere is defined as the region where isentropes cross the extratropical tropopause, thus enabling bidirectional exchange between both parts of the middleworld (Holton et al., 1995).

Correspondence to: P. Hoor

(hoor@mpch-mainz.mpg.de) 


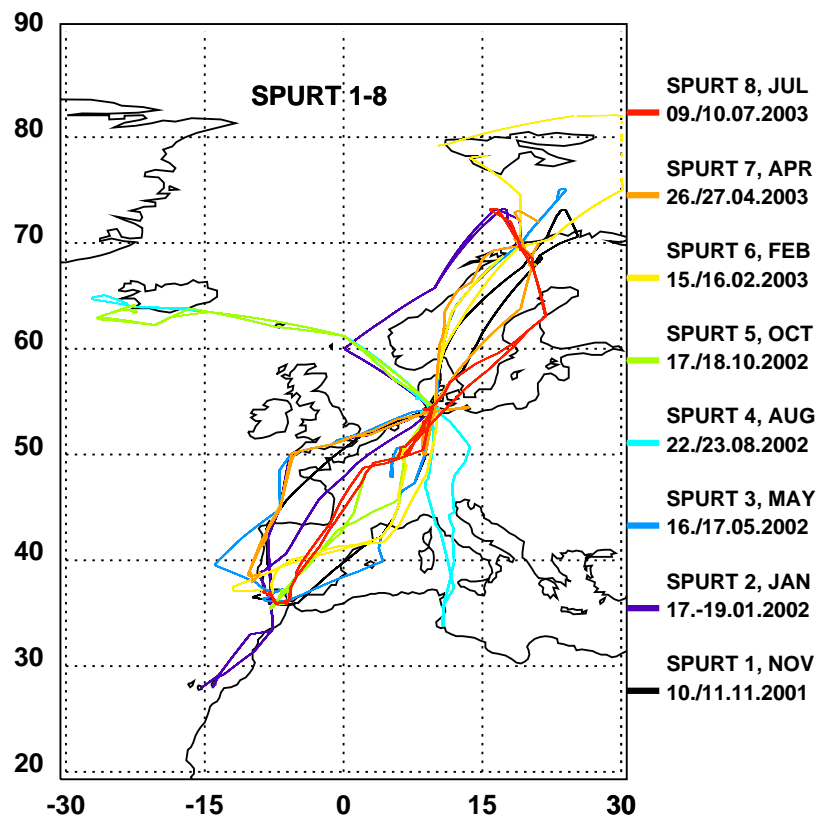

Fig. 1. Flight tracks for the SPURT missions from November 2001 to July 2003.

In the following we will use the terms TST for troposphere-to-stratosphere transport, STT for stratosphereto-troposphere transport, both characterizing the transfer of mass across the tropopause (Stohl et al., 2003) associated with a change of PV in the transported air parcel. The latter is a prerequisite for mixing. We will use the term mixing when we refer to an irreversible intermediate chemical composition of the involved air masses. STE (stratospheretroposphere exchange) refers to the bidirectional process.

Numerous in-situ measurements in the vicinity of tropopause folds confirmed that the tropopause in the extratropics is not totaly impermeable to transport and that STE occurs (e.g. Danielsen, 1968; Shapiro, 1980; Kritz et al., 1991). In addition, convection has been identified injecting boundary layer air directly into the lowermost stratosphere within several hours (Poulida et al., 1996; Fischer et al., 2003). Radiative processes associated with the decay of anticyclones also might play an important role for TST in the extratropics (Zierl and Wirth, 1997).

Besides these case studies, the results of Dessler et al. (1995), Fischer et al. (2000) and Hoor et al. (2002) indicated that the sum of these rather localized TST-processes result in the formation of a mixing layer in the lowermost stratosphere exhibiting the photochemical characteristic of both, the troposphere and the stratosphere. Water vapour measurements showed that TST occurs between $\Theta=320-360 \mathrm{~K}$, but indicated a weakening influence with increasing PV on each isentropic surface (Pan et al., 2000).

Model studies indicated only a weak seasonality of the strength of TST on global scales (Sprenger and Wernli, 2003) in contrast to STT. During summer the location of TST shifts to higher isentropic surfaces (Chen, 1995) exhibiting a secondary maximum at $\Theta=360 \mathrm{~K}$ (Sprenger and Wernli, 2003) possibly due to weaker $\mathrm{PV}$-gradients and therefore a reduced barrier to TST at the subtropical jet (Chen, 1995; Haynes and Shuckburgh, 2000).

Beside the seasonality it is still an open question how far the effect of TST and subsequent mixing extends into the lowermost stratosphere in the vertical (cross isentropic) as well as in the quasi-horizontal direction on isentropes. In the stratosphere the air masses associated with TST furthermore interact with the diabatic downward motion (James et al., 2003).

In-situ measurements addressing this question were limited by their temporal and spatial coverage. Ray et al. (1999) concluded from three balloon profiles at $34.5^{\circ} \mathrm{N}$ and $64^{\circ} \mathrm{N}$, respectively, that the late spring lowermost stratosphere was dominated by air, which descended from $\Theta>380 \mathrm{~K}$, whereas in September tropospheric air contributed to a fraction of 50-80\%. They concluded that the tropospheric fraction was mixed across the extratropical tropopause into the lowermost stratosphere. Based on two airborne measurement campaigns in Winter 1997 (northern Europe, 69 $9^{\circ} \mathrm{N}$ ) and summer 1998 (Canada, 48 ${ }^{\circ}$ N) Hoor et al. (2002) concluded that mixing across the extratropical tropopause results in the formation of a layer with higher vertical extent in summer than in winter.

The next section gives a short description of the SPURT project and the measurement concept followed by an overview of the experimental setup. After a description of the data coverage in the tropopause region we discuss exemplary CO-profiles and investigate implications for TST in the UT/LS region using the whole SPURT data set. Finally, we will focus on the tropospheric contribution to the stratospheric background air using long-lived tracers like $\mathrm{CO}_{2}$ and $\mathrm{N}_{2} \mathrm{O}$.

\section{Project Overview}

\subsection{The SPURT concept}

In 2001 the SPURT (trace gas transport in the tropopause region) project started to investigate dynamical and chemical processes affecting the chemical composition of the extratropical lowermost stratosphere. Although the investigation of TST was the prime focus of the project, single case studies of transport and mixing processes were a minor component of the project. Instead, a seasonal overview of the trace gas distribution in the tropopause region over a broad range of latitudes was investigated. The goal was to examine seasonal variations and the integral effect of individual TST-events on the trace gas composition of the lowermost stratosphere. Therefore, a total of eight airborne measurement campaigns were performed in different months 
Table 1. Instrumentation during SPURT.

\begin{tabular}{lll}
\hline species & technique & institute \\
\hline $\mathrm{CO}, \mathrm{N}_{2} \mathrm{O}, \mathrm{CH}_{4}$ & TDLAS & MPI Mainz \\
$\mathrm{CO}_{2}$ & NDIR (LiCor-6262) & MPI Mainz \\
$\mathrm{NO}, \mathrm{NO}_{\mathrm{y}}, \mathrm{O}_{3}$ & CLD + gold converter & ETH Zürich \\
$\mathrm{H}_{2} \mathrm{O}$ & Lyman- $\alpha$-fluorescence & FZ Jülich \\
$\mathrm{O}_{3}$ & UV-absorption & FZ Jülich \\
$\mathrm{N}_{2} \mathrm{O}, \mathrm{F}-12, \mathrm{SF}_{6}$ & in-situ GC & University Frankfurt/Main \\
\hline
\end{tabular}

between 2001 and 2003. Home base was Hohn (northern Germany, $52^{\circ} \mathrm{N}, 8^{\circ} \mathrm{E}$ ). A typical campaign consisted of two northbound and two southbound flights, respectively, covering a latitude range from approximately $35^{\circ} \mathrm{N}$ to $75^{\circ} \mathrm{N}$ (Fig. 1). The flights were performed on two consecutive days and sampled a snapshot of the trace gas distribution in the tropopause region over Europe for a given meteorological situation. Flight planning for each campaign was based on the meteorological forecast provided by the ETH Zürich using operational ECMWF-data. In particular the PV-fields were used to deduce the location of the tropopause for the planning of the individual flights.

Each flight typically consisted of two long flight legs at constant altitude, one leg within the tropopause region and the second one high above in the lowermost stratosphere. At the end of each flight the aircraft climbed to maximum altitude in order to sample undisturbed stratospheric background air followed by a slow descent providing high resolution vertical profiles. Intermediate landings were made close to the most southerly and northerly points resulting in a total of eight vertical profiles per campaign at different latitudes. The successive flight on the same day mirrored the flight pattern such that each point along the flight path was sampled at two different altitudes, which was not always possible due to aircraft limitations and air traffic restrictions.

\subsection{Experimental setup}

A Lear Jet 35 operated by GFD (Gesellschaft für Flugzieldarstellung) in cooperation with the company enviscope was used as measurement platform. The aircraft is capable of reaching a maximum flight altitude of $13.7 \mathrm{~km}$ and has a range of approximately $2000 \mathrm{~km}$ at a cruising speed of $150 \mathrm{~m} / \mathrm{s}$. Table 1 gives an overview of the payload and lists the measured species and the techniques used. The trace gas measurements were supplemented by measurements of meteorological parameters such as pressure, temperature and horizontal winds.

$\mathrm{CO}, \mathrm{CH}_{4}$ and $\mathrm{N}_{2} \mathrm{O}$ were measured with the Tunable Diode Laser Absorption Spectrometer (TDLAS) TRISTAR (Tracer in situ TDLAS for atmospheric research) (Wienhold et al., 1998; Kormann et al., 2002). Time multiplexing is achieved by pneumatically driven pop-up mirrors allowing subsequent measurement of each species with an integration time of $1.5 \mathrm{~s}$. The time resolution is ultimately limited by the summed integration times for the three measurement channels resulting in a duty cycle of less than $5 \mathrm{~s}$ for each species. The instrument is calibrated in-flight using secondary standards of dried ambient air, whose concentrations are crosscalibrated prior to and after the campaigns against a laboratory long term standard. To guarantee consistency over the different campaigns the long term laboratory standard is traced to NOAA standards. The total uncertainty for $\mathrm{N}_{2} \mathrm{O}$, $\mathrm{CO}$ and $\mathrm{CH}_{4}$ is better than $1 \%, 1.5 \%$ and $2.5 \%$, respectively. These values have to be taken as upper limits since the precision is determined from the reproducibility of the in-flight calibrations, thus mainly mirroring the slow drifts of the instrument sensitivity, which are accounted for in the subsequent data processing. Furthermore, $\mathrm{N}_{2} \mathrm{O}$ is measured independently by the in-situ GC GHOST (University of Frankfurt/Main). Both techniques yield an excellent agreement of 98\% (H. Bönisch, personal communication).

A LICOR 6262 was used to determine $\mathrm{CO}_{2}$ mixing ratios with a time resolution of $1 \mathrm{~Hz}$. A constant-pressure inlet allows the instrument to operate at a pressure of $850( \pm 0.1) \mathrm{hPa}$. The instrument temperature was stabilized to $40.0^{\circ} \mathrm{C}$. Ambient $\mathrm{CO}_{2}$ is determined against a reference gas of known $\mathrm{CO}_{2}$ concentration. In-flight calibrations are performed with two secondary standards of compressed dried air, bracketing the expected ambient values. The standards are cross-calibrated against two NOAA CMDL primary standards. Total uncertainty of the measurements is better than $0.1 \%$.

Ozone has been measured using a chemiluminescence detector (ECO-Physics SR-790) with an overall accuracy of $5 \%$. The detector has been calibrated before and after each measurement campaign using a commercial ozone calibrator.

Meteorological forecasts and analysis data were provided by the ETH-Zürich and were based on the 3-h operational ECMWF data with 60 vertical levels corresponding to a height resolution of about $700 \mathrm{~m}$ at the extratropical tropopause. The meteorological post-flight analysis included the calculation of ten-day backward trajectories (Wernli and Davies, 1997) which were initialized every ten seconds along the flight track, providing information in particular on the history of PV and $\Theta$ of the encountered air masses.

\section{Data coverage}

As mentioned earlier, the main focus of SPURT was to establish an overview of the chemical composition in the tropopause region. For this purpose a sufficient data coverage is crucial. Figure 2 displays the total observation time binned with respect to potential temperature $\Theta$ and latitude for all eight campaigns. Superimposed is the tropopause-potential temperature (denoted $\Theta_{T P}$ in the following) interpolated 

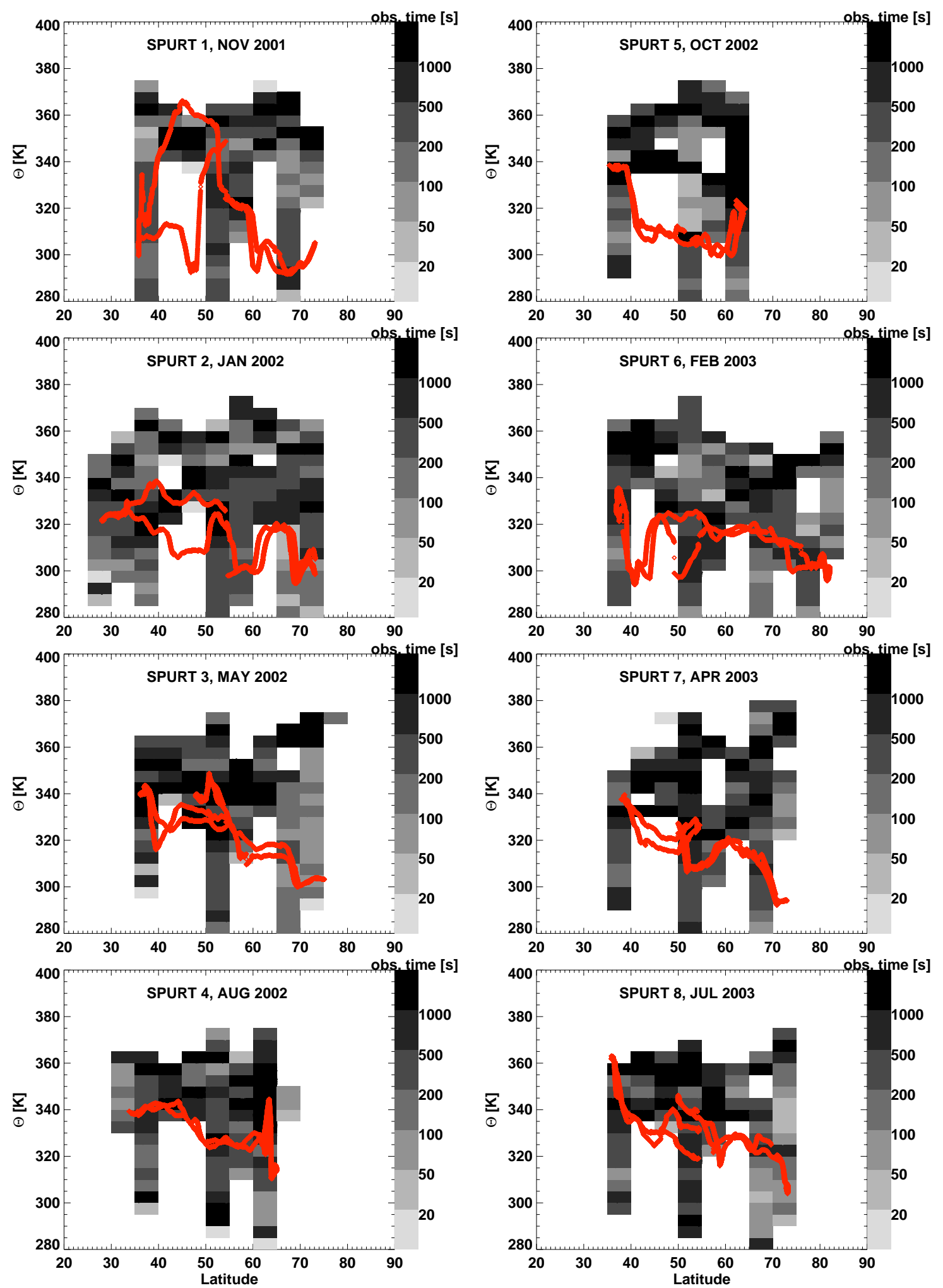

Fig. 2. Data coverage for SPURT as a function of latitude and potential temperature $\Theta$. The location of the local tropopause at the position of the aircraft is superimposed. Note the variability of potential temperature at the tropopause during each deployment. 
along the flight path. Although it was not possible to completely cover the region above the local tropopause, a dense coverage was achieved from $35-75^{\circ} \mathrm{N}$ up to $\Theta=360 \mathrm{~K}$. The two flights to Iceland during SPURT 4 in August 2002 and SPURT 5 in October 2002 resulted in a smaller latitude range for these missions.

The data, which were sampled during each individual measurement campaign covered a broad range of meteorological situations due to meridional northward advection of (sub-)tropical tropospheric air or southward excursions of stratospheric air, both associated with large variations of the tropopause altitude along the flight path. A detailed description of the meteorological situation during each individual flight is beyond the scope of this study and will be given in a separate article. Here, we focus on the temporal and spatial distribution of trace gases in the tropopause region to deduce the extent of TST in the lowermost stratosphere.

The trace gas composition of a single air parcel can be regarded as the sum of several independent individual mixing events and thus represents a spectrum of different air masses and mixing time scales. Therefore a detailed analysis of the meteorological situation during each individual flight is not essential for the understanding of the trace gas distribution in the lowermost stratosphere. However, knowledge of the geographical location of the local tropopause relative to the location of the measurements is crucial to separate tropospheric and stratospheric air.

For the following analysis we used a dynamical definition of the tropopause based on a value of 2 PVU (1 PVU $=10^{-6} \mathrm{~m}^{2} \mathrm{~K} \mathrm{~s}^{-1} \mathrm{~kg}^{-1}$ ). Although the tropopause was crossed at different $\Theta$-levels several times during each campaign, an in-situ, tracer- or temperature-based tropopause definition is not feasible since the aircraft flew most of the times in varying distances above or below the tropopause.

During each campaign at least the $\Theta=370 \mathrm{~K}$ isentropic surface was crossed generally high above the local tropopause, allowing the characterization of stratospheric air far from recent extratropical tropospheric influence, but close to the lower boundary of the overworld.

\section{Results}

\subsection{Irreversibility of TST}

To identify TST and subsequent mixing across the extratropical tropopause we used the relation between $\mathrm{CO}$ and $\mathrm{N}_{2} \mathrm{O}$. The most important source for $\mathrm{CO}$ in the stratosphere is the photochemical degradation of $\mathrm{CH}_{4}$ via $\mathrm{OH}$. Destruction of $\mathrm{CO}$ takes place via the reaction with $\mathrm{OH}$ forming $\mathrm{CO}_{2}$ resulting in a lifetime of $\mathrm{CO}$ on the order of several months. If no additional $\mathrm{CO}$ from the troposphere is mixed into the stratosphere, a steady state volume mixing ratio of $8-15$ ppbv establishes, which is the balance between photochemical production from $\mathrm{CH}_{4}$ and the much faster $\mathrm{CO}$ oxidation via $\mathrm{OH}$
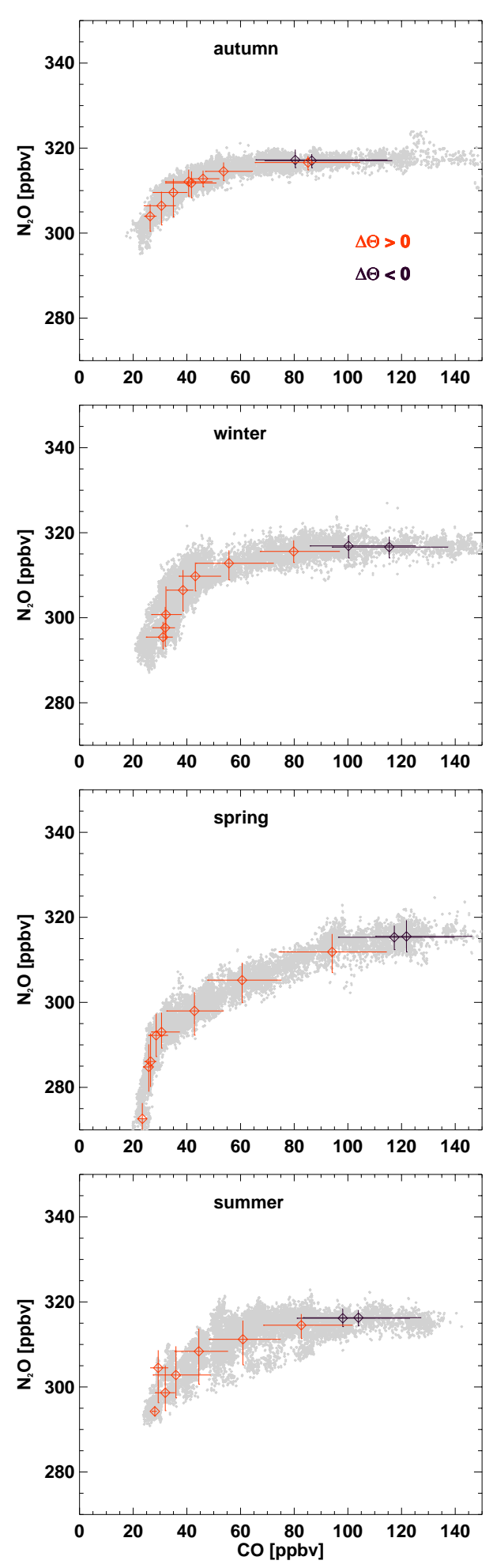

Fig. 3. Scatter plots of $\mathrm{N}_{2} \mathrm{O}$ and $\mathrm{CO}$ merged for different seasons. Colored symbols show the medians relative to the PV $=2$ PVUsurface binned in steps of $\Delta \Theta=10 \mathrm{~K}$ (see text for details). Bars show the variability in each bin centered at the respective means. 


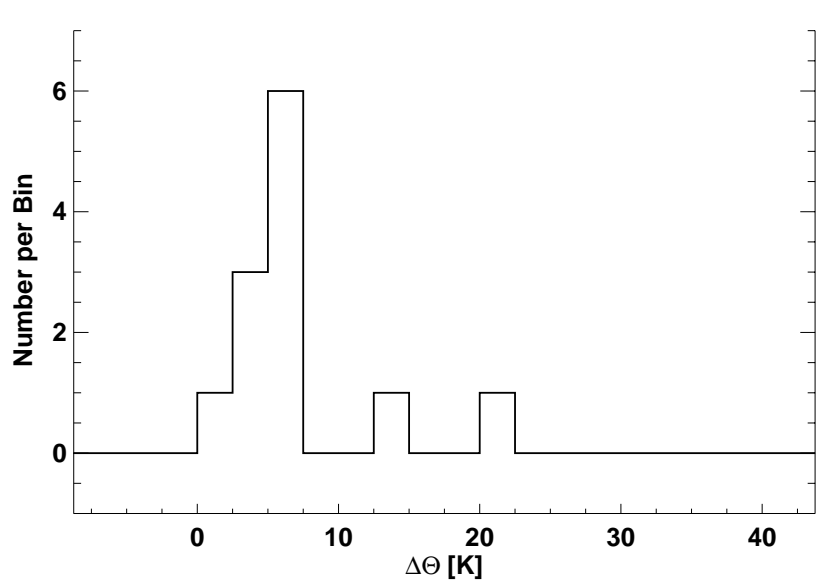

Fig. 4. Comparison of thermal and dynamical tropopause for the SPURT flights showing the distribution of $\Delta \Theta$ at the thermal tropopause. Details see text.

(Flocke et al., 1999). High altitude measurements by the ER2 in the tropics as well as in polar regions indicated almost constant CO-values of 12 ppbv (Flocke et al., 1999; Toon et al., 1999). In the stratosphere near the local tropopause in general values above this background are observed reflecting transport of tropospheric air into the stratosphere. Thus, in the stratosphere any excess $\mathrm{CO}$ above the equilibrium level indicates a contribution of air of tropospheric origin.

The sources of $\mathrm{N}_{2} \mathrm{O}$ are at the earth's surface. Unlike CO, tropospheric $\mathrm{N}_{2} \mathrm{O}$ is well mixed giving a rather constant tropospheric mean value of 317 ppbv. It's major sink is in the tropical stratosphere where it is destroyed via photolysis and reaction with $\mathrm{O}\left({ }^{1} \mathrm{D}\right)$. The long local photochemical lifetime on the order of 120 years (Volk et al., 1997) leads to much weaker $\mathrm{N}_{2} \mathrm{O}$-gradients at the tropopause than for $\mathrm{O}_{3}$, but makes it ideal to trace stratospheric transport since $\mathrm{N}_{2} \mathrm{O}$ is not affected by local photochemistry. In a CO- $\mathrm{N}_{2} \mathrm{O}$ scatter-plot mixing of air across the tropopause leads to the formation of positive correlations among both species. In particular, intermediate $\mathrm{CO}$ between tropospheric values and stratospheric background at decreasing $\mathrm{N}_{2} \mathrm{O}$-levels clearly indicates irreversible mixing of tropospheric air into the lowermost stratosphere.

As illustrated in Fig. 3 the $\mathrm{N}_{2} \mathrm{O}$-CO-relationship exhibits rather compact slopes over different seasons towards higher altitudes (i.e. lower $\mathrm{N}_{2} \mathrm{O}$-values). Lowest $\mathrm{N}_{2} \mathrm{O}$ values are found during winter and spring, respectively, accompanied with the steepest slopes of the $\mathrm{N}_{2} \mathrm{O}-\mathrm{CO}$ correlation. Both findings indicate a stronger contribution of photochemically aged stratospheric air in the lowermost stratosphere compared to summer and autumn. The transition from tropospheric to stratospheric air in Fig. 3 is indicated by intermediate values of $\mathrm{CO}$ at decreasing levels of $\mathrm{N}_{2} \mathrm{O}$.

Since we are interested in the extent of isentropic mixing in the lowermost stratosphere we analyzed our data in poten- tial temperature coordinates relative to the local tropopause $(\Delta \Theta[\mathrm{K}]) . \Delta \Theta$ was deduced from ECMWF-data by calculating the difference between $\Theta$ and $\Theta_{T P}$ at the PV $=2$ PVUsurface along the flight path. A single PV-value of two PVU seems to be somewhat arbitrary since PV-values ranging from 1.5-3.5 PVU have been used to define the extratropical tropopause (e.g. WMO (1986); Hoerling et al. (1991)).

However, it is evident from Fig. 3 that an almost constant tropospheric $\mathrm{N}_{2} \mathrm{O}$-value of $317 \mathrm{ppbv}$ indicative for tropospheric air is found at $\Delta \Theta<0$ (i.e. PV $<2$ PVU). Above, the decrease of $\mathrm{N}_{2} \mathrm{O}$ starts within $\Delta \Theta=10 \mathrm{~K}$ above the local tropopause. If the PV-threshold of $2 \mathrm{PVU}$ were too far off the tropopause, the rapid overturning and mixing would have destroyed a stratospheric $\mathrm{N}_{2} \mathrm{O}$-signature in the troposphere on timescales of hours to days.

We compared the thermal and the dynamical tropopause definition for vertical profiles reaching sufficiently high into the stratosphere to apply the thermal criterion (lowest level, where temperature lapse rate is exceeding $-2 \mathrm{~K} / \mathrm{km}$ with the average lapse rate within the next 2 kilometers above not falling below $-2 \mathrm{~K} / \mathrm{km}$ ). Fig. 4 shows that on average the dynamical tropopause is found slightly below the thermal tropopause in agreement with the results of Hoerling et al. (1991) and Bethan et al. (1996). When we use a less restrictive criterion by averaging the temperatures only within one kilometer to account for higher tropopause altitudes (not shown) the signature becomes even stronger with $80 \%$ of thermal tropopauses falling into the bin below $\Delta \Theta=7.5 \mathrm{~K}$. As indicated by Wirth (2001) the bias of the thermal tropopause towards a higher PV-threshold partly arises from the choice of the $-2 \mathrm{~K} / \mathrm{km}$ criterion. Using a lapse rate threshold which is closer to the average of typical tropospheric and stratospheric lapse rates, respectively, the discrepancies are reduced.

Note that the observation of decreasing $\mathrm{N}_{2} \mathrm{O}$ above $\Delta \Theta=0$ (equivalent to $\mathrm{PV}=2 \mathrm{PVU}$ ) which indicates persistent stratospheric influence in the $\Delta \Theta=0-10 \mathrm{~K}$ bin, illustrates that the photochemical transition from the troposphere into stratosphere falls into that region. The almost tropospheric trace gas signature in the $\Delta \Theta=0-10 \mathrm{~K}$-bin during autumn can be due to the weak contribution of overworld air in late summer/autumn (Ray et al., 1999) leading to weak $\mathrm{N}_{2} \mathrm{O}$ gradients at the tropopause, but might also arise from the choice of a single PV-value of $2 \mathrm{PVU}$ for the tropopause. Thus, in the following the latter may result in an upper limit of distances relative to the local tropopause, when dealing with $\Delta \Theta$, but as indicated in Fig. 3 and Fig. 4 this offset is in general on the order of $\Delta \Theta=5-7.5 \mathrm{~K}$. Therefore, Fig. 3 illustrates that the dynamical tropopause defined as the PV = 2 PVU-surface is a good approximation for the tropopause in our measurement region.

Focussing on mixing processes at the extratropical tropopause rather than the stratospheric background the correlation of $\mathrm{CO}$ and $\mathrm{O}_{3}$ is more appropriate due to the stronger gradient of ozone at the tropopause. In a CO-O $\mathrm{O}_{3}$ scatter-plot 
mixing of air across the tropopause leads to the formation of mixing lines connecting stratospheric background and upper tropospheric $\mathrm{CO}$ - and $\mathrm{O}_{3}$-values, respectively. Note, that the appearance of mixing lines associated with an intermediate chemical composition of air in the lowermost stratosphere indicates the irreversibility of the mixing process. The method is described in detail in Fischer et al. (2000) and Hoor et al. (2002).

Figure 5 displays the $\mathrm{CO}-\mathrm{O}_{3}$-scatterplot for the campaign in February 2003. A rather compact anticorrelation covering almost the entire range of stratospheric $\mathrm{O}_{3}$-mixing ratios is evident. Just above the tropopause $\mathrm{O}_{3}$ mixing ratios between $100-300$ ppbv accompanied by CO values ranging from 40 $75 \mathrm{ppbv}$ indicate a mixture of tropospheric and stratospheric air. A close inspection reveals distinct mixing lines indicating mixing from recent TST-events of various tropospheric origins. Different CO concentrations in the upper troposphere, which are involved in these mixing events result in the observed different slopes of the individual mixing lines. However, most points form the broad compact central band which can be regarded as the sum of individual mixing events that are already completed and possibly remixed, thus forming a "smoothed" mean slope. This major part of the correlation is therefore independent from the current meteorological situation which on the other hand may determine individual mixing lines.

Higher up in the lowermost stratosphere at ozone levels exceeding $300 \mathrm{ppbv}$, the slope of the anticorrelation becomes steeper and less scattered, indicating a layer with different air mass characteristics. In particular individual mixing lines that connect directly to the local tropopause are absent despite the large data coverage during SPURT 6 (comp. Fig. 2). Note that TST and subsequent mixing associated even with a small amount of tropospheric air would appear as a mixing line in such a scatter plot as long as mixing is incomplete.

The absence of mixing lines above $\mathrm{O}_{3}>300 \mathrm{ppbv}$ and the steep and compact anti-correlation indicate that recent injections from the extratropical troposphere are of minor importance in this part of the stratosphere. Nevertheless, tropospheric influence is still evident due to the fact that observed $\mathrm{CO}$-values ranging from $20-45 \mathrm{ppbv}$ significantly exceed the stratospheric equilibrium value. The rather sharp transition between these two layers in the lowermost stratosphere indicates two regions with a different degree of tropospheric influence, different air mass histories and possibly mixing time scales.

4.2 Trace gas profiles and vertical structure of the lowermost stratosphere

Figure 6a shows the whole CO-dataset which was obtained from the five mission flights during SPURT 6 using $\Theta$ as vertical coordinate. The tropopause altitude along the flight tracks during this campaign varied between $350 \mathrm{hPa}$ and $200 \mathrm{hPa}$, corresponding to variations in $\Theta_{T P}$ from 295-

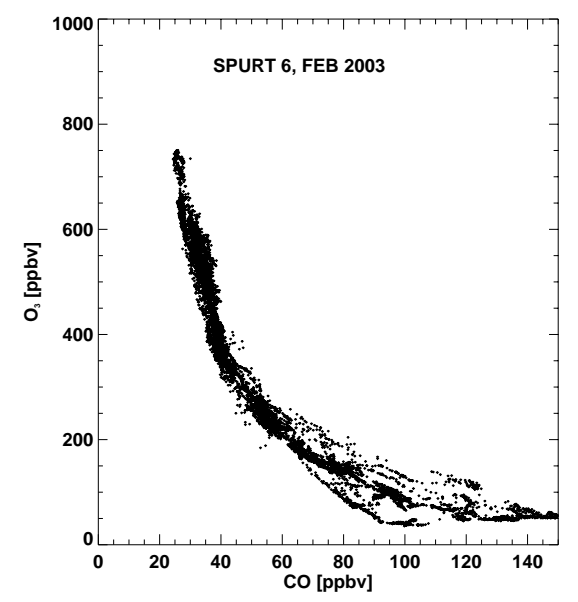

Fig. 5. Scatterplot of $\mathrm{CO}$ and ozone for SPURT 6 in February 2003. Taking an ozone threshold of $100 \mathrm{ppbv}$ as an approximation for the tropopause the anticorrelation indicates irreversible cross tropopause mixing. Note, that at $\mathrm{O}_{3}=300 \mathrm{ppbv}$ the slope abruptly changes indicating a rather sharp transition between different layers.

$335 \mathrm{~K}$ (compare Fig. 2). A large part of the scatter in Fig. 6a is due to this variation of the tropopause potential temperature $\Theta_{T P}$. In particular no significant upper or lower boundary for tropospheric influence becomes evident.

The picture changes significantly, if potential temperature relative to the local tropopause $(\Delta \Theta[\mathrm{K}])$ is used as a vertical coordinate. In Fig. $6 \mathrm{~b}$ the $\mathrm{CO}$ data from SPURT 6 are shown as a function of $\Delta \Theta$ instead of $\Theta$. The profile exhibits less scatter resulting in a much higher compactness. In contrast to Fig. 6a the vertical distribution now displays a kink at $\Delta \Theta=25 \mathrm{~K}$ separating two regimes of different chemical composition within the lowermost stratosphere. Just above the local tropopause $\mathrm{CO}$ decreases rapidly within a layer of $\Delta \Theta=25 \mathrm{~K}$ from tropospheric values down to mixing ratios of less than 45 ppbv. At greater vertical distances from the tropopause the decrease of $\mathrm{CO}$ is much more gradual leading to a steeper $\mathrm{CO}$ gradient than directly above the tropopause.

The change of gradient in the vertical CO-profile which appears at $\Delta \Theta=25 \mathrm{~K}$ corresponds to a mean $\mathrm{CO}$ value of 45 ppbv. Note that the kink in the $\mathrm{CO}_{3} \mathrm{O}_{3}$ scatter plot (Fig. 5) is evident at the same $\mathrm{CO}$ value separating photochemically aged air and a layer which is influenced by recent mixing as indicated by distinct mixing lines in Fig. 5. Thus, the respective region between the local tropopause and $\Delta \Theta<25 \mathrm{~K}$ (Fig. 6b) is strongly influenced by recent TST-events and subsequent mixing at the extratropical tropopause. It is interesting to note that the overall effect of different individual processes and events exhibits a common upper boundary, although the data were collected over a broad latitude range $\left(35^{\circ}-85^{\circ} \mathrm{N}\right)$ and variations of $\Theta_{T P}$ from $295 \mathrm{~K}-335 \mathrm{~K}$.

A similar behaviour can also be identified from other trace gas measurements. For example, $\mathrm{CO}_{2}$ exhibits almost the 
(a)

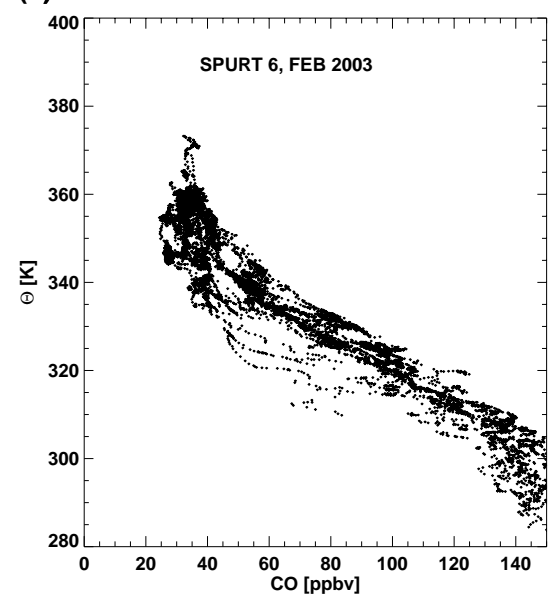

(b)

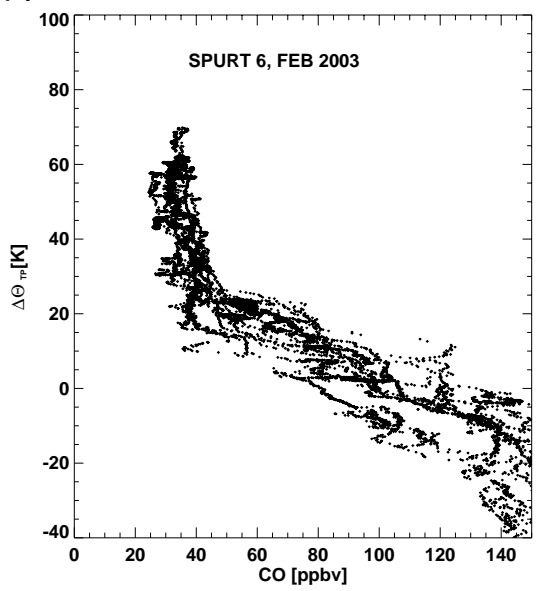

(c)

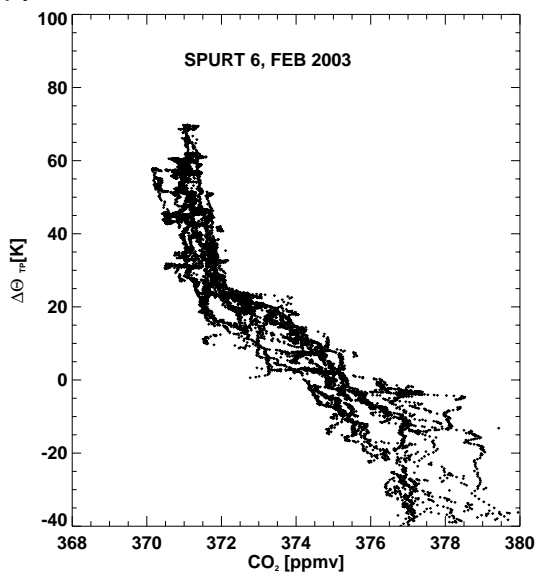

Fig. 6. (a) Complete CO data set obtained during the SPURT 6 missions as a function of (a) potential temperature and (b) potential temperature relative to the local tropopause $\Delta \Theta$. Note the more compact $\Delta \Theta$-profile and the rather sharp change of the $\mathrm{CO}$ gradient at $\Delta \Theta=25 \mathrm{~K}$. (c) $\mathrm{CO}_{2}$ as a function of $\Delta \Theta$ during SPURT 6 showing the same behaviour at $\Delta \Theta=25 \mathrm{~K}$.
Table 2. Statistical dependencies for the profiles of $\mathrm{CO}$ versus $\Theta$, $\Delta \Theta$ and PV during SPURT.

\begin{tabular}{lcccc}
\hline \multirow{2}{*}{ campaign } & date & \multicolumn{3}{c}{ Spearmans $\rho$ : CO vs. } \\
& & $\Theta$ & $\Delta \Theta$ & PV \\
\hline SPURT 1, NOV & $10 .-11.11 .2001$ & -0.71 & -0.85 & -0.91 \\
SPURT 2, JAN & $17 .-19.01 .2002$ & -0.85 & -0.94 & -0.89 \\
SPURT 3, MAY & $16 .-17.05 .2002$ & -0.88 & -0.94 & -0.90 \\
SPURT 4, AUG & $22 .-23.08 .2002$ & -0.80 & -0.89 & -0.85 \\
SPURT 5, OCT & $17 .-18.10 .2002$ & -0.75 & -0.89 & -0.79 \\
SPURT 6, FEB & $16 .-17.02 .2003$ & -0.80 & -0.87 & -0.74 \\
SPURT 7, APR & $26 .-27.04 .2003$ & -0.89 & -0.94 & -0.84 \\
SPURT 8, JUL & $09 .-10.07 .2003$ & -0.75 & -0.87 & -0.78 \\
\hline
\end{tabular}

same vertical distribution relative to $\Delta \Theta$ (Fig. 6c) including a sharp transition at $\Delta \Theta=25 \mathrm{~K}$. Since $\mathrm{CO}_{2}$ has no photochemical sinks in the lowermost stratosphere its distribution is exclusively controlled by dynamics. It is thus unlikely that the structure seen in the CO-distribution was caused predominantly by photochemical degradation associated with a longer residence time in this part of the lowermost stratosphere. Instead, the sharp change of gradient of the COand $\mathrm{CO}_{2}$-profiles at $\Delta \Theta=25 \mathrm{~K}$ separates air masses with different fractions of tropospheric air, thus different histories, within the lowermost stratosphere. This rather well pronounced separation in the lowermost stratosphere marked by the "kink" in the vertical CO- and $\mathrm{CO}_{2}-\Delta \Theta$ profiles (Fig. 6b and Fig. 6c) and the $\mathrm{CO}_{3} \mathrm{O}_{3}$-correlation (Fig. 5) was found during all campaigns independent of season or latitude.

The most compact relationships appeared between $\mathrm{CO}$ and $\Delta \Theta$ (Table 2). We used Spearmans' rank correlation to compare the correlation between $\mathrm{CO}$ and the respective parameters since it is independent of the "shape" of the distribution. Thus we don't have to make any assumptions on the functional relationship between $\mathrm{CO}$ and the respective parameters (Press et al., 1999). Although the definition of $\Delta \Theta$ is based on $\mathrm{PV}(\mathrm{PV}=2 \mathrm{PVU})$ a stronger correlation between $\mathrm{CO}$ and $\Delta \Theta$ than for $\mathrm{CO}$ and $\mathrm{PV}$ is found. On the one hand $\Theta$ is determined from in-situ measurements of pressure and temperature whereas PV is calculated on a coarse grid. On the other hand PV-gradients might determine trace gas distributions rather than absolute values of PV. The fact that the highest degree of correlation appears between $\Delta \Theta$ and $\mathrm{CO}$ implies that the CO-distribution in the lowermost stratosphere is more dependent on the vertical distance from the local tropopause than on the absolute $\Theta$-value of the isentropic surface. This has consequences for the extent of the TST-impact in the lowermost stratosphere which will be discussed in the next section. 


\section{Discussion}

\subsection{Seasonal variation of the mixing layer}

To investigate the horizontal extent of the TST-impact along isentropic surfaces we used the $\Theta$-equivalent latitude coordinate system. Equivalent latitude $\phi_{e q}$ can be obtained by transforming the area that is enclosed by a PV-contour on a given isentrope to a pole-centered circle of equal area. The distance of the respective PV-circles from the equator in degrees latitude represents $\phi_{e q}$, forming a unique relation between PV and $\phi_{e q}$ on each isentropic surface. The $\phi_{e q}-\Theta-$ coordinate system can be regarded as tropopause-following since it follows the meridional excursions of PV-contours induced by planetary waves. Using a value of PV $=2 \mathrm{PVU}$ (associated to a unique $\phi_{e q}$ ) for the extratropical tropopause, trace gas mixing ratios, which are displayed in this coordinate system, therefore appear according to their distance to the local tropopause on a given isentropic surface. For SPURT PV- $\phi_{e q}$-relations have been calculated for 37 individual isentropes from $\Theta=270-400 \mathrm{~K}$ in steps of $5 \mathrm{~K}$. The equivalent latitude of each measurement point then was obtained by bilinear interpolation from the discrete $\phi_{e q}(\mathrm{PV}, \Theta)$ distribution to the PV- and $\Theta$-values at the observation.

Figure 7 shows the distribution of $\mathrm{CO}$ for the whole set of SPURT missions mapped onto $\phi_{e q}-\Theta$-coordinates. In the troposphere $\mathrm{CO}$ exhibits significant latitudinal gradients in agreement with the climatology of $\mathrm{CO}$ for the northern hemisphere (e.g. Emmons et al., 2000; Herman et al., 1999; Zahn et al., 2004). The strongest decline of CO mixing ratios is observed in a layer from PV $=2-6$ PVU (black lines), where $\mathrm{CO}$ decreases from tropospheric values down to less than 50 ppbv. Thus, the CO-isopleths in the lowermost stratosphere are non-parallel to isentropes resulting in a tropopause-following layer structure independent from season. As stated in the previous section, these $\mathrm{CO}$ mixing ratios from 50-80 ppbv indicate a mixture of tropospheric and stratospheric air. Moreover, the existence of a tropopausefollowing layer implies that the effect of mixing out of this layer further into the lowermost stratosphere is only weak or the processes are slow since CO-gradients extend along isentropes further into the lowermost stratosphere.

In Fig. 7 the positions of ten-day backward trajectories are superimposed, which indicated TST and ended along the stratospheric part of the flights (black dots). We selected only TST-trajectories that spent at least $24 \mathrm{~h}$ in both the troposphere and stratosphere, respectively. If quasi-horizontal mixing of tropospheric air deep into the lowermost stratosphere were fast, one could expect a large spread of TST trajectories on isentropic surfaces. However, this is not observed. Almost all TST-trajectories end in close proximity to the local tropopause below 6 PVU and $\Delta \Theta<20 \mathrm{~K}$. The distribution of TST as indicated by the TST-trajectories roughly matches the distribution of regions with elevated $\mathrm{CO}$ in the stratosphere and supports the hypothesis that TST and sub- sequent mixing along isentropes on short time scales mainly affect a layer close to the local tropopause.

The picture deduced from the absolute $\mathrm{CO}$ volume mixing ratio might be biased by the seasonal and latitudinal variations of $\mathrm{CO}$ in the troposphere. From Fig. 7 it is difficult to deduce a seasonality of the extent of mixing or to conclude on variations of the layer depth.

Therefore, we selected all $\mathrm{CO}$ data in the region between $\Delta \Theta=-5-0 \mathrm{~K}$ and interpolated these data along $\Theta_{T P}$ giving upper tropospheric $\mathrm{CO}\left(\mathrm{CO}_{U T}\right)$. We furthermore assumed a background equilibrium value of $12 \mathrm{ppbv}$ (referred to as $\mathrm{CO}_{b k g d}$ ) being representative for undisturbed stratospheric air. To obtain a measure for the tropospheric $\mathrm{CO}$-fraction $\left(\mathrm{CO}_{T S}\right)$ the ratio $\mathrm{CO}_{T S}=\left(\mathrm{CO}-\mathrm{CO}_{b k g d}\right) /\left(\mathrm{CO}_{U T}-\mathrm{CO}_{b k g d}\right)$ was calculated. $\mathrm{CO}_{T S}$ should be independent of the seasonal and latitudinal variations of tropospheric $\mathrm{CO}$-values, and thus reflect predominantly the effect of TST and mixing on time scales of days to weeks.

Note, that the fraction $\mathrm{CO}_{T S}$ without any additional information is not equal to the mass fraction of tropospheric air in the lowermost stratosphere due to the limited photochemical lifetime of $\mathrm{CO}$ on the order of three months. In the stratosphere the $\mathrm{CO}$ mixing ratio of an air parcel is not only determined by mixing but also by photochemical degradation depending on the time since its last contact to the troposphere. Thus, the approach provides a lower limit for the fraction of tropospheric air in the lowermost stratosphere since photochemical degradation of $\mathrm{CO}$ is not accounted for.

The distribution of the $\mathrm{CO}_{T S}$ in $\phi_{e q}-\Delta \Theta$-coordinates (Fig. 8) confirms the conclusions which are drawn from the absolute $\mathrm{CO}$ volume mixing ratios in Fig. 7. The large enhancements in November 2001 result from a southbound flight in the vicinity of a deep stratospheric intrusion adjacent to a tropospheric ridge with $\Theta_{T P}>360 \mathrm{~K}$ (see Fig. 2) and an almost vertical dynamical tropopause, indicative of a tropopause break. Since $\Delta \Theta$ is defined as the vertical distance from the PV $=2 \mathrm{PVU}$-surface a vertical tropopause results in very large $\Delta \Theta$-values (compare SPURT 1 in Fig. 7 and Fig. 8). The system was associated with a strong jet as well as convective activity ahead of the surface cold front. A detailed case study by Hegglin et al. (2003) suggests that this convective activity over the southwestern Mediterranean, which was associated with intense lightning activity, was responsible for the injection of significant amounts of $\mathrm{NO}_{\mathrm{y}}$ and water vapor into the lowermost stratosphere.

The use of $\Delta \Theta$ instead of $\Theta$ in Fig. 8 illustrates that isolines of constant tropospheric fraction roughly follow the tropopause $(\Delta \Theta=0)$. A ratio of $\mathrm{CO}_{T S}=40 \%$ approximates the $1 /$ e-photochemical lifetime $(37 \%)$ which we use as a measure for extratropical TST and subsequent mixing within the CO-lifetime. With the exception of the outstanding SPURT 1-campaign the distributions for the corresponding seasons over different years show similar patterns. Largest layer depths and variabilities of the tropospheric fraction are observed during the summer campaigns. 

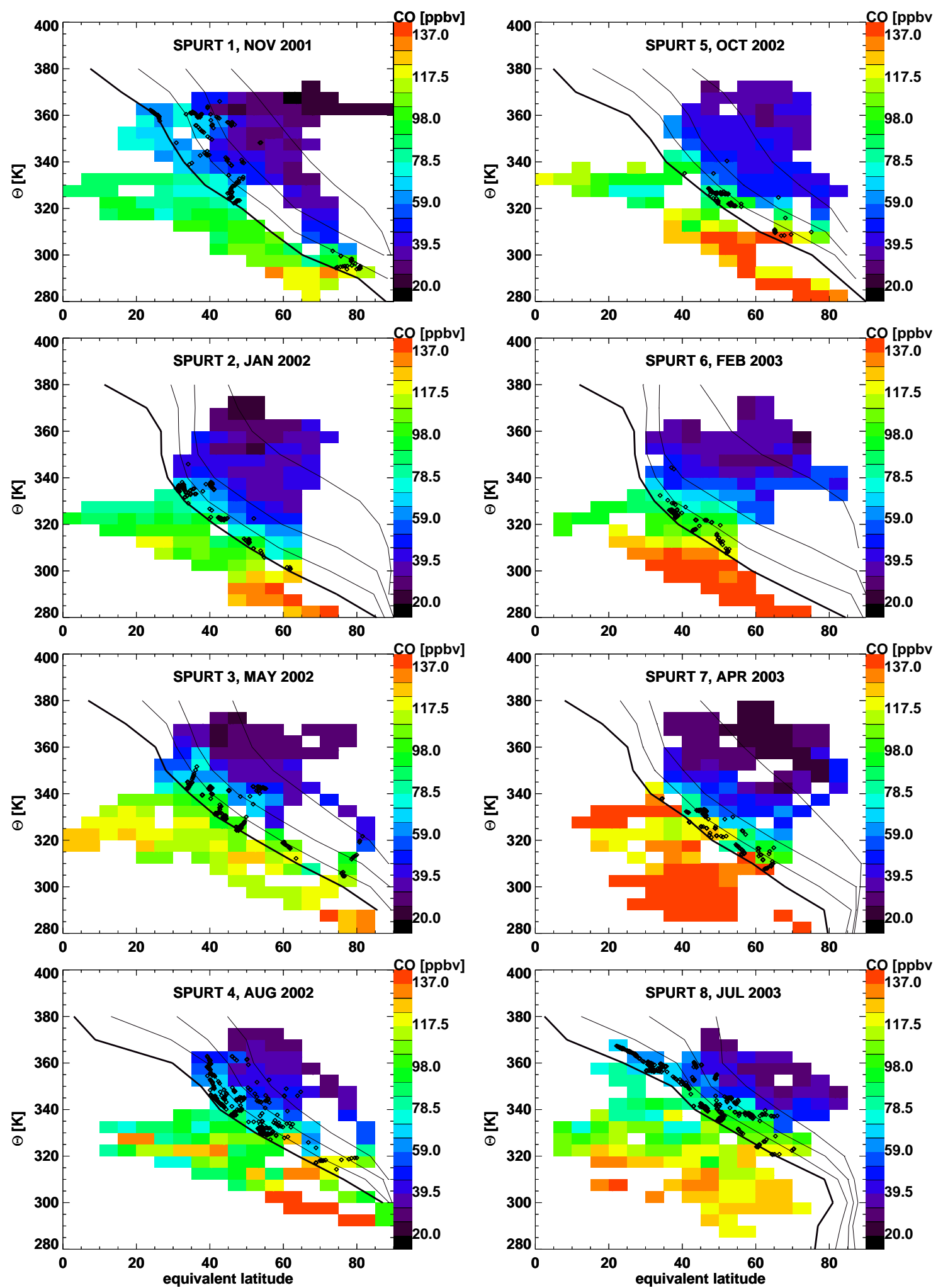

Fig. 7. CO-distribution in equivalent latitude $\phi_{e q}-\Theta$-coordinates for the whole SPURT-deployment. The thick black line denotes the location of the tropopause PV = 2 PVU-surface, thin lines mark the 4,6 and 8 PVU-contours, respectively. Superimposed are the positions of 10-day backward trajectories indicating TST within ten days before the flights. 

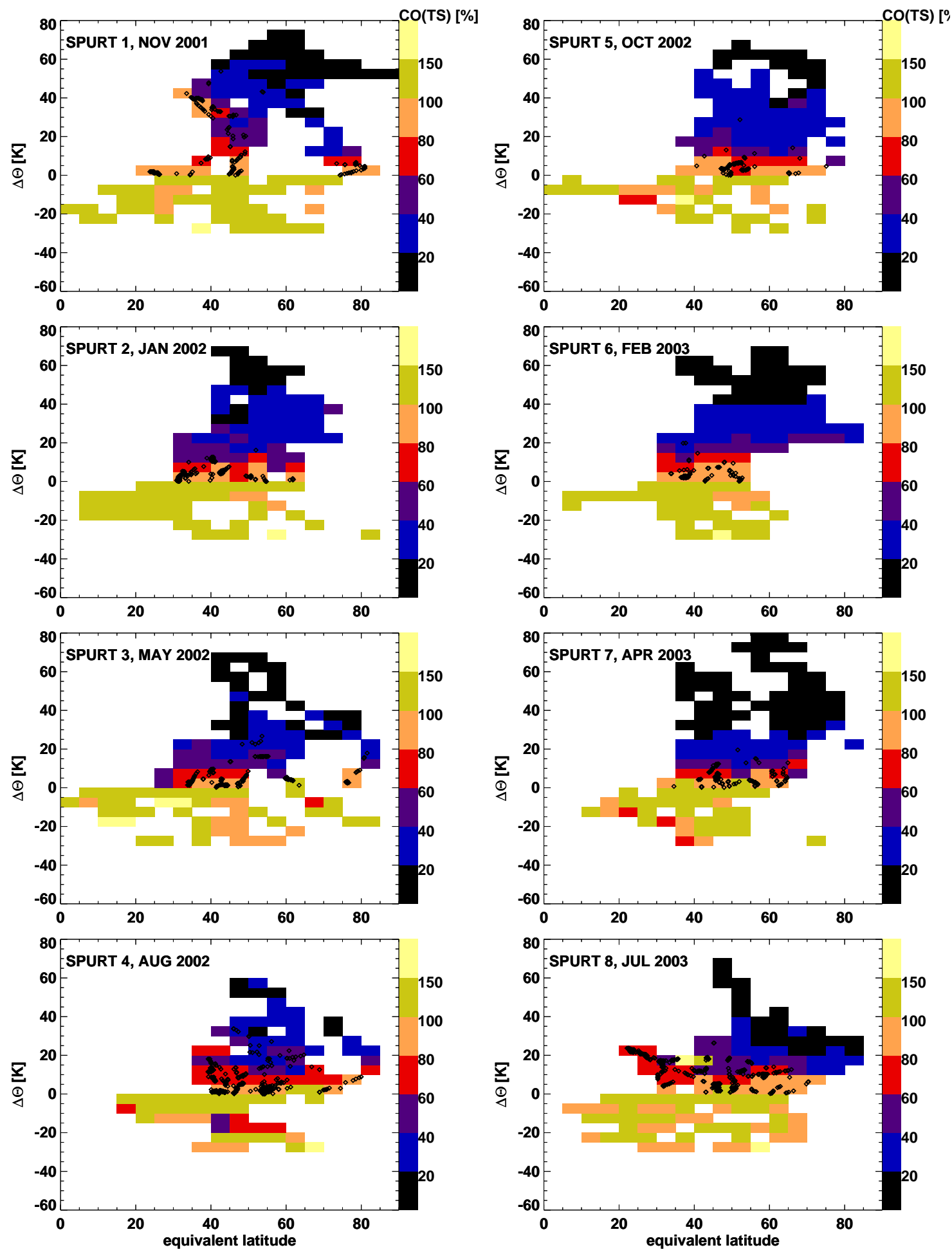

Fig. 8. Tropospheric fraction of $\mathrm{CO}$ relative to the respective isentropic tropopause CO-value in Fig. 7 as a function of equivalent latitude and $\Delta \Theta$ above the tropopause (details see text). 


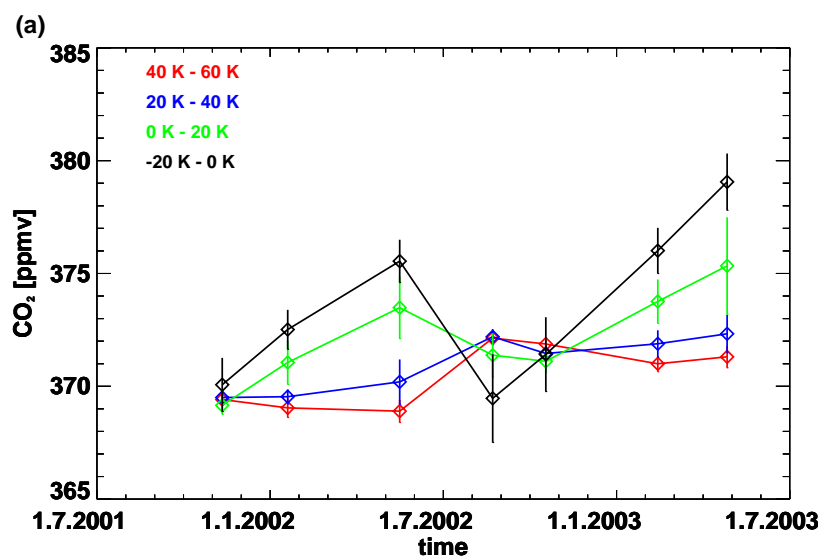

(b)

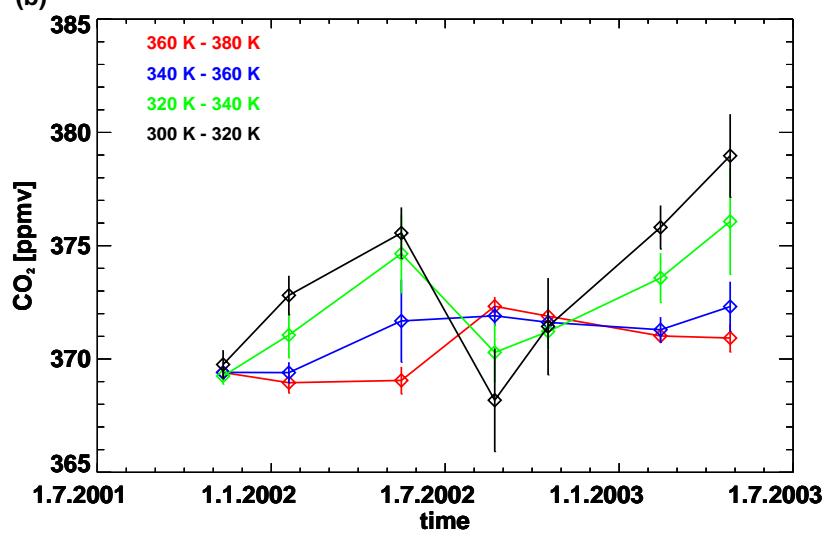

Fig. 9. (a) $\mathrm{CO}_{2}$ as a function of time and $\Delta \Theta$ above the local tropopause. The phase shift at $\Delta \Theta>20 \mathrm{~K}$ is evident. (b) $\mathrm{CO}_{2}$ on isentropic surfaces. Note the local maximum in summer on the highest isentropic surface of $\Theta=360 \mathrm{~K}$ and the negative vertical $\mathrm{CO}_{2}$ gradient in August 2002.

During the rest of the year a rather homogenous layer structure was found rarely exceeding $\Delta \Theta=20 \mathrm{~K}$. Note, that in case of a homogenous CO-distribution on isentropic surfaces one would expect an increasing layer depth at higher $\phi_{e q}$ due to the sloping tropopause on isentropic surfaces (comp. Fig. 7). Instead, rather constant mixing layer depths in terms of $\Delta \Theta[\mathrm{K}]$ or even increasing layer depths towards low latitudes are observed (SPURT 1, SPURT 4, SPURT 8). In Fig. 8 the stratospheric end points of TST-trajectories are again superimposed. The trajectories indeed correspond to air parcels showing an enhanced tropospheric CO-fraction. In particular during SPURT 1 and SPURT $4 \mathrm{CO}_{T S}$ and TST-trajectories both indicate significant TST within the last 10 days. Note the large vertical spread of trajectory-indicated TST during summer in agreement with a higher mixing layer depths deduced from the tropospheric CO-fraction.

A larger depth of the summer mixing layer is in agreement with the seasonal cycle found in theoretical studies (Chen, 1995; Haynes and Shuckburgh, 2000) and the measurement- based conclusions by Hoor et al. (2002). Moreover, during summer a stronger tropospheric contribution is indicated towards lower equivalent latitudes, which is in close agreement with an additional maximum for TST near $\Theta=360 \mathrm{~K}$ (Sprenger and Wernli, 2003). In contrast, during winter diabatic downward transport from the overworld maximizes (Appenzeller et al., 1996; Pan et al., 2000) leading to a stronger contribution of overworld air filling the lowermost stratosphere with photochemically aged CO-depleted air during late winter/spring.

Therefore, we conclude that only the lowest $\Delta \Theta=20 \mathrm{~K}$ (30 K during summer) above the tropopause are influenced by TST and subsequent mixing with extratropical tropospheric air on time scales of days to a few weeks.

\subsection{Beyond the mixing layer}

Beyond the mixing layer above the tropopause, $\mathrm{CO}$ mixing ratios higher than the undisturbed stratospheric $\mathrm{CO}$ equilibrium value indicate that the air cannot be regarded as purely stratospheric from a photochemical point of view. In this part of the lower stratosphere either time scales for mixing have to be longer, allowing CO to be photochemically processed, or the amount of tropospheric air reaching these distances from the tropopause is smaller. To address mixing processes exceeding the $\mathrm{CO}$-lifetime we used relations between long-lived tracers like $\mathrm{N}_{2} \mathrm{O}$ with a photochemical lifetime of 100 years and $\mathrm{CO}_{2}$ which is virtually inert in the lower stratosphere.

$\mathrm{CO}_{2}$ with its well known tropospheric seasonal cycle provides useful informations on the transit time scale and the tropospheric origin of the mixed air masses. In Fig. 9 upper tropospheric $\mathrm{CO}_{2}(\Delta \Theta=-20-0 \mathrm{~K})$ shows a strong seasonal cycle with a springtime maximum in May 2002 and April 2003, respectively. The minimum is found during summer which is in accordance with measurements of Nakazawa et al. (1991). Just above the tropopause at $(\Delta \Theta=0-20 \mathrm{~K})$ the same seasonal pattern is evident which confirms the strong coupling between the lowermost stratosphere and the extratropical troposphere through TST and subsequent mixing in accordance with the analysis in the previous section. The dampening of the amplitude of the seasonal cycle reflects the role of the extratropical tropopause as a barrier to transport. Above $\Delta \Theta=20 \mathrm{~K}$ the phase maximum is shifted towards summer. The delay of three months indicates a phase lag due to longer transit times for the tropospheric fraction of air, which is mixed into the lowermost stratosphere, and possibly a different transport path. The observation of distinct seasonal cycles of $\mathrm{CO}_{2}$ at a certain distance relative to the local tropopause is in agreement with other measurements. Ozone sonde data evaluated at the thermal tropopause and $2 \mathrm{~km}$ above exhibit different seasonal cycles (Logan, 1999) which illustrates the separation between the mixing layer and the lowermost stratosphere. 
To investigate if isentropic mixing delayed by three months can account for the observed phase lag in the lowermost stratosphere, we evaluated the seasonal cycle of $\mathrm{CO}_{2}$ on isentropic surfaces (Fig. 9b). Similar to Fig. 9a a clear phase shift is evident between $\Theta=320 \mathrm{~K}$ and $360 \mathrm{~K}$. At $\Theta=340 \mathrm{~K}$ no distinct minima or maxima occur due to averaging the $\mathrm{CO}_{2}$ seasonal cycles from the mixing layer $(\Delta \Theta<20 \mathrm{~K})$ and the lower stratospheric background $(\Delta \Theta>20 \mathrm{~K})$. The isentropic view reveals that isentropic mixing from the extratropics cannot account for the observed phase signal. The $\mathrm{CO}_{2}$ maximum which is found above $\Theta=360 \mathrm{~K}$ in August 2002 exceeds any value which was measured during the preceeding campaigns in the same layer. Therefore it cannot be regarded as a remnant of isentropic cross tropopause mixing during the previous months. Similarly, local cross isentropic transport from tropospheric altitudes (e.g. through convection) cannot account for the phase maximum at the highest isentropic surfaces observed in August 2002 due to the negative vertical $\mathrm{CO}_{2}$-gradient during summer.

If TST and subsequent mixing in the extratropics cannot account for the tropospheric fraction of air in the lowermost stratosphere, the air most likely entered the stratosphere at the tropical tropopause. To find a tropical signature in our data we analyzed the correlation between $\mathrm{CO}_{2}$ and $\mathrm{N}_{2} \mathrm{O}$. Both species are long-lived enough to obey the conditions for slope equilibrium (Plumb and Ko, 1992) i.e. their isopleths are controlled by dynamics as opposed to photochemistry. We evaluated the correlation for $\Delta \Theta>45 \mathrm{~K}$ to exclude recent TST and mixing from the extratropics, but to have a statistically significant data base (300-1100 data points per campaign). Following Hintsa et al. (1999) we applied a linear fit to the reduced $\mathrm{N}_{2} \mathrm{O}-\mathrm{CO}_{2}$-relationship and extrapolated the tropospheric end member of $\mathrm{CO}_{2}$ assuming a tropopause value of 317 ppbv for $\mathrm{N}_{2} \mathrm{O}$ (WMO, 2003). The applied fit method accounts for the uncertainties in both measurements (Press et al., 1999) and returns the standard deviation of the parameters.

Figure 10 displays the deduced tropospheric $\mathrm{CO}_{2}$ end members for the SPURT-camapaigns as well as the average of the surface data of Samoa and Mauna Loa (Keeling and Whorf, 2003). We found that a backward timeshift of 2.5 months gave the best agreement between the extrapolated tropical SPURT $\mathrm{CO}_{2}$ tropopause values and the averaged surface cycles. Andrews et al. (1999) showed that at $\Theta=390 \mathrm{~K}$ the maximum of the seasonal cycle occurs in early July in agreement with observations of Boering et al. (1996) who used a delay of two months for the propagation of the surface signal to these altitudes. Since the phase maximum occurs around mid June in the tropical troposphere (Nakazawa et al., 1991; Matsueda and Inoue, 1996) the air most likely entered the tropical stratosphere at $\Theta=380 \mathrm{~K}$ between mid June and the beginning of July resulting in a horizontal transport time to high latitudes of about one month which is in close agreement with Boering et al. (1996).

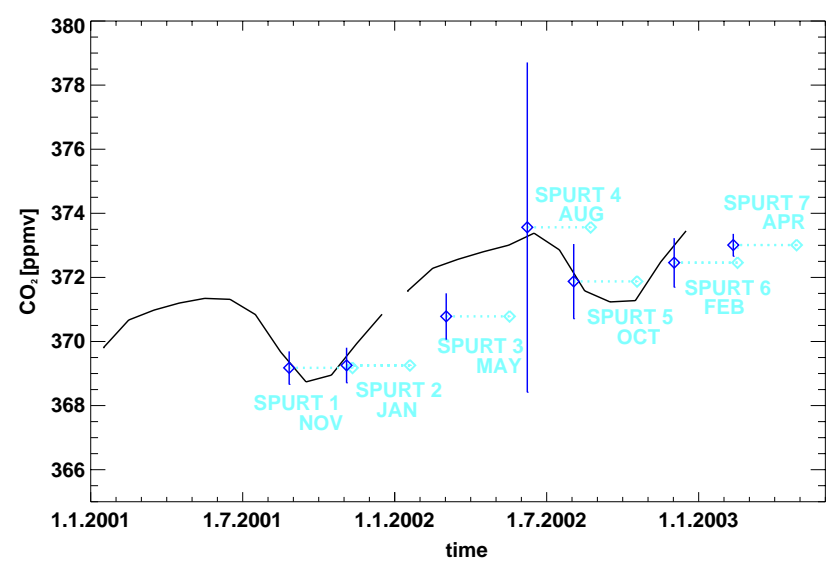

Fig. 10. Tropical $\mathrm{CO}_{2}$ surface data and tropical tropopause $\mathrm{CO}_{2}-$ data deduced from SPURT shifted backward in time by 2.5 months (dark blue), light blue: time of measurement. Error bars are deduced from the error of the fit parameters of the $\mathrm{N}_{2} \mathrm{O}-\mathrm{CO}_{2}-$ correlation for $\Delta \Theta>45 \mathrm{~K}$ (details see text).

The large error bar for the summer campaign is the result of a data base of only 300 points and a large scatter of the data resulting in a poor correlation coefficient. For the spring missions in May 2002 (SPURT 3) and April 2003 (SPURT 7), respectively, a time lag of 2.5 months is too short to match the tropical seasonal cycle. The extrapolated $\mathrm{CO}_{2}$ tropopause values from SPURT indicate a longer transient time since tropospheric entry. Most likely the springtime lowermost stratosphere carries a larger contribution of aged air from higher altitudes which descended from $\Theta>380 \mathrm{~K}$. The net downward mass transport across the $380 \mathrm{~K}$ isentropic surface maximizes during winter (Appenzeller et al., 1996) leading to an increasing fraction of photochemically aged air in late winter and spring in the lowermost stratosphere. Thus, the contribution of air masses with a longer transit time since last contact with the tropical tropopause is larger than during the rest of the year.

Ray et al. (1999) stated that the lowermost stratosphere is more strongly influenced by air descending from above $\Theta>380 \mathrm{~K}$ during springtime than at the end of summer. Our results show a similar pattern, however we can identify a significant contribution of air originating from the tropical tropopause in the extratropical lowermost stratosphere. Ray et al. (1999) addressed the tropospheric influence in their data to mixing across the extratropical tropopause. However, this transport pathway cannot explain the propagation of the seasonal $\mathrm{CO}_{2}$-cycle on different isentropic surfaces which is observed during SPURT.

Therefore, we conclude that the lowermost stratosphere above $\Delta \Theta=30 \mathrm{~K}$ is significantly affected by tropospheric air, that entered the stratosphere at the tropical tropopause. According to Rosenlof et al. (1997) these air masses are partly transported quasi horizontally to midand high latitudes within 2-4 months where they mix with 
photochemically aged air which diabatically descends from the overworld. Grewe et al. (2002) calculated transport timescales of not more than 1.5 months for tropical tropospheric air being transported to the extratropical lowermost stratosphere. In agreement with observations Andrews et al. (2001) found, that stratospheric $\mathrm{CO}_{2}$ time series (for $\mathrm{N}_{2} \mathrm{O}>255$ ppbv) are represented best by bimodal age spectra. For $\mathrm{N}_{2} \mathrm{O}>275$ ppbv the younger peak indicates a mean transit time of only several weeks. The aforementioned studies reveal that a significant amount of air that enters the stratosphere at the tropical tropopause is transported quasihorizontally within a few weeks to months to higher latitudes. Diabatic descent (Appenzeller et al., 1996) from $\Theta>380 \mathrm{~K}$ leads to the observed tropical contribution of air in the lowermost stratospheric background far from the extratropical tropopause. Closer to the extratropical tropopause the phase shift of $\mathrm{CO}_{2}$ between $\Delta \Theta<0 \mathrm{~K}$ and $\Delta \Theta>20 \mathrm{~K}$ suggests, that TST and mixing in the extratropics dominates over the diabatically descending tropical tropospheric fraction of air.

\section{Conclusions}

The extensive data set obtained during the SPURT missions facilitated a broad overview of the seasonal distribution of trace gases over Europe. The CO distribution in the lowermost stratosphere indicates the existence of a mixing layer which establishes above the local tropopause. The mixing layer exhibits trace gas signatures being characteristic for a mixture of young tropospheric and stratospheric air. The depth of the layer exhibits a weak seasonal cycle showing the largest elevation of $\Delta \Theta=30 \mathrm{~K}$ above the local tropopause in summer and $20-25 \mathrm{~K}$ during the rest of the year. The seasonal cycle of $\mathrm{CO}_{2}$ in the mixing layer shows the same phase as in the troposphere illustrating the strong coupling between both regions. Within the lowermost stratosphere the influence of TST and subsequent mixing decreases with distance from the local tropopause in both vertical and horizontal direction resulting in a mixing layer which closely follows the local tropopause. Based on ER-2 measurements of CO and $\mathrm{O}_{3}$ Pan et al. (2003) ${ }^{1}$ suggested the extratropical tropopause can be viewed as a layer characterized by intermediate tracer mixing ratios due to rapid and shallow exchange (Stohl et al., 2003). Similar conclusions based on trajectory calculations have been drawn from James et al. (2003) showing that layers of the same age are a function of distance to the tropopause and not of isentropic surfaces in agreement with the observed $\mathrm{CO}$ isopleths during SPURT.

At larger distances from the local tropopause the $\mathrm{CO}_{2}$ phase lag as well as $\mathrm{CO}$ values exceeding the stratospheric

\footnotetext{
${ }^{1}$ Pan, L., Randel, W., Browell, E., Gary, B., Mahoney, M., and Hintsa, E.: Definitions and sharpness of the extratropical tropopause: A trace gas perspective, submitted to J. Geophys. Res., 2003.
}

steady state mixing ratio both indicate tropospheric influence, but on different transient- and mixing time scales. From the relationship between $\mathrm{CO}_{2}$ and $\mathrm{N}_{2} \mathrm{O}$ and tropical surface data we could determine an average transport time of 2.5 months from the tropics to the extratropical lowermost stratosphere above $\Theta=370 \mathrm{~K}$. Due to the strong downwelling in the extratropics during winter the contribution of overworld air is enhanced in accordance with Ray et al. (1999).

Acknowledgements. Without the excellent support by the company GFD (Gesellschaft für Flugzieldarstellung) in cooperation with the company enviscope in operating the Lear Jet the whole SPURT project would not have been possible. We are grateful to the German Ministry for Education and Research for financial support within the AFO-2000 programme and to the Swiss National Fond.

Edited by: A. Stohl

\section{References}

Andrews, A. E., Boering, K. A., Wofsy, S. C., Daube, B. C., Hintsa, E. J., Weinstock, E. M., and Bui, T. P.: Empirical age spectra for the lower tropical stratosphere from in situ observations of $\mathrm{CO}_{2}$ : Implications for stratospheric transport, J. Geophys. Res., 104, 26 581-26 595, 1999.

Andrews, A. E., Boering, K. A., Wofsy, S. C., Daube, B. C., Jones, D. B., Alex, S., Loewenstein, M., Podolske, J. R., and Strahan, S. E.: Empirical age spectra for the midlatitude lower stratosphere from in-situ observations of $\mathrm{CO}_{2}$ : Quantitative evidence for a subtropical "barrier" to horizontal transport, J. Geophys. Res., 106, 10 257-10 274, 2001.

Appenzeller, C., Holton, J. R., and Rosenlof, K. H.: Seasonal variation of mass transport across the tropopause, J. Geophys. Res., 101, 15 071-15 078, 1996.

Bethan, S., Vaughan, G., and Reid, S. J.: A comparison of ozone and thermal tropopause heights and the impact of tropopause definition on quantifying the ozone content of the tropopause, Q. J. R. Meteorol. Soc., 122, 929-944, 1996.

Boering, K. A., Wofsy, S. C., Daube, B. C., Schneider, J. R., Loewenstein, M., Podolske, J. R., and Conway, T. J.: Stratospheric mean ages and transport rates from observations of $\mathrm{CO}_{2}$ and $\mathrm{N}_{2} \mathrm{O}$, Science, 274, 1340-1343, 1996.

Chen, P.: Isentropic cross tropopause mas exchange in the extratropics, J. Geophys. Res., 100, 16 661-16673, 1995.

Danielsen, E. F.: Stratospheric-tropospheric exchange based upon radioactivity, ozone, and potential vorticity, J. Atmos. Sci., 25, 502-518, 1968.

Dessler, A. E., Hintsa, E. J., Weinstock, E. M., Anderson, J. G., and Chan, K. R.: Mechanism controlling water vapor in the lower stratosphere: A tale of two stratospheres, J. Geophys. Res., 100, 23 167-23 172, 1995.

Emmons, L. K., Hauglustaine, D. A., Müller, J.-F., Carrol, M. A., Brasseur, G. P., Brunner, D., Staehelin, J., Thourét, V., and Marenco, A.: Data composites of airborne observations of tropospheric ozone and its precursors, J. Geophys. Res., 105, $20497-$ $20538,2000$. 
Fischer, H., Wienhold, F. G., Hoor, P., Bujok, O., Schiller, C., Siegmund, P., Ambaum, M., Scheeren, H. A., and Lelieveld, J.: Tracer correlations in the northern high latitude lowermost stratosphere: Influence of cross-tropopause mass exchange, Geophys. Res. Lett., 27, 97-100, 2000.

Fischer, H., de Reus, M., Traub, M., Williams, J., Lelieveld, J., de Gouw, J., Warneke, C., Schlager, H., Minikin, A., Scheele, R., and Siegmund, P.: Deep convective injection of boundary layer air into the lowermost stratosphere at midlatitudes, Atmos. Chem. Phys., 3, 739-745, 2003,

SRef-ID: 1680-7324/acp/2003-3-739.

Flocke, F., Herman, R. L., Salawitch, R. J., Atlas, E., Webster, C. R., Schauffler, S. M., Lueb, R. A., May, R. D., Moyer, E. J., Rosenlof, K. H., Scott, D. C., Blake, D. R., and Bui, T. P.: An examination of chemistry and transport processes in the tropical lower stratosphere using observations of long-lived and shortlived compounds obtained during STRAT and POLARIS, J. Geophys. Res., 104, 26 625-26 642, 1999.

Grewe, V., Reithmeier, C., and Shindell, D. T.: Dynamic-chemical coupling of the upper troposphere and lower stratosphere region, Chemosphere: Global Change Science, 47, 851-861, 2002.

Haynes, P. and Shuckburgh, E.: Effective diffusivity as a diagnostic of atmospheric transport, 2., Troposphere and lower stratosphere, J. Geophys. Res., 105, 22 795-22 810, 2000.

Hegglin, M. I., Brunner, D., Wernli, H., Schwierz, C., Martius, O., Krebsbach, M., Schiller, C., Spelten, N., Hoor, P., Fischer, H., Parchatka, U., Weers, U., Staehelin, J., and Peter, T.: Tracing troposphere to stratosphere transport within a mid-latitude deep convective system, Atmos. Chem. Phys. Discuss., 105, 22 795$22810,2003$.

Herman, R. L., Webster, C. R., May, R. D., Scott, D. C., Hu, H., Moyer, E. J., Wennberg, P. O., Hanisco, T. F., Lanzendorf, E. J., Salawitch, R. J., Yung, Y. L., Margitan, J. J., and Bui, T. P.: Measurements of $\mathrm{CO}$ in the upper troposphere and lower stratosphere, Chemosphere: Global Change Science, 1, 173183, 1999.

Hintsa, E. J., Boering, K. A., Weinstock, E. M., Anderson, J. G., Gary, B. L., Pfister, L., Daube, B. C., Wofsy, S. C., Loewenstein, M., Podolske, J. R., Margitan, J. J., and Bui, T. P.: Troposphere-to-stratosphere transport in the lowermost stratosphere from measurements of $\mathrm{H}_{2} \mathrm{O}, \mathrm{CO}_{2}, \mathrm{~N}_{2} \mathrm{O}$ and $\mathrm{O}_{3}$, Geophys. Res. Lett., 25, 2655-2658, 1999.

Hoerling, M. P., Schaack, T. K., and Lenzen, A. J.: Global objective tropopause analysis, Mon. Weather Rev., 119, 1816-1831, 1991.

Holton, J. R., Haynes, P. H., McIntyre, M. E., Douglass, A. R., Rood, R. B., and Pfister, L.: Stratosphere-troposphere exchange, Rev. Geoph., 33, 403-439, 1995.

Hoor, P., Fischer, H., Lange, L., Lelieveld, J., and Brunner, D.: Seasonal variations of a mixing layer in the lowermost stratosphere as identified by the $\mathrm{CO}-\mathrm{O}_{3}$ correlation from in situ measurements, J. Geophys. Res., 107, 4044, doi:10.1029/2000JD000 289, 2002.

Hoskins, B. J.: Towards a PV- $\Theta$-view of the general circulation, Tellus, Ser. A/B, 43, 27-35, 1991.

James, P., Stohl, A., Forster, C., Eckhardt, S., Seibert, P., and Frank, A.: A 15-year climatology of stratospheretroposphere exchange with a Lagrangian particle dispersion model: 1. Methodology and validation, J. Geophys. Res., 108, doi:10.1029/2002JD002 637, 2003.
Keeling, C. D. and Whorf, T. P.: Atmospheric $\mathrm{CO}_{2}$ records from sites in the SIO air sampling network, Carbon Dioxide Information Analysis Center, Oak Ridge National Laboratory, U.S. Department of Energy, Oak Ridge, Tenn., USA, 2003.

Kormann, R., Fischer, H., Gurk, C., Helleis, F., Klüpfel, T., Kowalski, K., Königstedt, R., Parchatka, U., and Wagner, V.: Application of a multi-laser tunable diode laser absorption spectrometer for atmospheric trace gas measurements at sub-ppbv levels, Spectrochim. Acta A, 58, 2489-2498, 2002.

Kritz, M. A., Rosner, S. W., Danielsen, E. F., and Selkirk, H. B.: Air mass origins and troposphere to stratosphere exchange associated with mid-latitude cyclogenesis and tropopause folding inferred from ${ }^{7}$ Be measurements, J. Geophys. Res., 96, 17 405-17414, 1991.

Lacis, A. A., Wuebbles, D. J., and Logan, J. A.: Radiative forcing of climate by changes in the vertical distribution of ozone, J. Geophys. Res., 95, 9971-9981, 1990.

Logan, J. A.: An analysis of ozonesonde data for the troposphere: Recommendations for testing 3-D models and development of a gridded climatology for tropospheric ozone, J. Geophys. Res. 104, 16 115-16 149, 1999.

Matsueda, $\mathrm{H}$. and Inoue, $\mathrm{H}$.: Measurements of atmospheric $\mathrm{CO}_{2}$ and $\mathrm{CH}_{4}$ using a commercial airliner from 1993 to 1994, Atmos. Environ., 30, 1647-1655, 1996.

Nakazawa, T., Miyashita, K., Aoki, S., and Tanaka, M.: Temporal and spatial variations of upper tropospheric and lower stratospheric carbon dioxide, Tellus, 43B, 106-117, 1991.

Pan, L., Hintsa, E., Stone, E., Weinstock, E., and Randel, W.: The seasonal cycle of water vapor and saturation vapor mixing ratio in the extratropical lowermost stratosphere, J. Geophys. Res., $105,26519-26530,2000$.

Plumb, R. A. and Ko, M. K. W.: Interrelationships between mixing ratios of long-lived stratospheric constituents, J. Geophys. Res., 97, $10145-10156,1992$

Poulida, O., Dickerson, R. R., and Heymsfield, A.: Stratospheretroposphere exchange in a mid latitude mesoscale convective complex, 1. Observations, J. Geophys. Res., 101, 6823-6836, 1996.

Press, W. H., Vetterling, W., Teukolsky, S., and Flannery, B.: Numerical recipes in Fortran 77: The art of scientific computing, Cambridge University Press, 2 edn., 1999.

Ray, E. A., Moore, F. L., Elkins, J. W., Dutton, G. S., Fahey, D. W., Vömel, H., Oltmans, S. J., and Rosenlof, K. H.: Transport into the Northern Hemisphere lowermost stratosphere revealed by in situ tracer measurements, J. Geophys. Res., 104, 26 565-26 580, 1999.

Rosenlof, K. H., Tuck, A. F., Kelly, K. K., Russel, J. M., and McCormick, M. P.: Hemispheric asymmetries in water vapor and inferences about transport in the lower stratosphere, J. Geophys. Res., 102, 13 213-13 234, 1997.

Shapiro, M. A.: Turbulent mixing within tropopause folds as a mechanism for the exchange of chemical constituents between the stratosphere and troposphere, J. Atmos. Sci., 37, 994-1004, 1980.

Sprenger, M. and Wernli, H.: A northern hemispheric climatology of cross-tropopause exchange for the ERA15 time period (19791993), J. Geophys. Res., 108, doi:10.1029/2002JD002 636, 2003. 
Stohl, A., Wernli, H., James, P., Bourqui, M., Forster, C., Liniger, M. A., Seibert, P., and Sprenger, M.: A new perspective of stratosphere-troposphere exchange, Bull. Am. Met. Soc., 84, 1565-1573, 2003.

Toon, G. C., Blavier, J.-F., Sen, B., Margitan, J. J., Webster, C. R., Max, R. D., Fahey, D. W., Gao, R., DelNegro, L., Proffitt, M., Elkins, J., Romashkin, P. A., Hurst, D. F., Oltmans, S., Atlas, E., Schauffler, S., Flocke, F., Bui, T. P., Stimpfle, R. M., Bonne, G. P., Voss, P. B., and Cohen, R. C.: Comparison of MkIV balloon and ER-2 aircraft measurements of atmospheric trace gases, J. Geophys. Res., 104, 26 779-26790, 1999.

Volk, C. M., Elkins, J. W., Fahey, D. W., Dutton, G. S., Gilligan, J. M., Loewenstein, M., Podolske, J. R., Chan, K. R., Gunson, M. R.: Evaluation of source gas lifetimes from stratospheric observations, J. Geophys. Res., 102, 25 543-25 564, 1997.

Wernli, H. and Davies, H. C.: A Lagrangian based analysis of extratropical cyclones, 1, The method and some applications, Q. J. R. Meteorol. Soc., 123, 467-489, 1997.
Wienhold, F., Fischer, H., Hoor, P., Wagner, V., Konigstedt, R., Harris, G., Anders, J., Grisar, R., Knothe, M., Riedel, W., Lübken, F., and T., S.: TRISTAR - a tracer in situ TDLAS for atmospheric research, App. Phys. B-Lasers and Optics, 67, 411-417, 1998.

Wirth, V.: Cyclone-anticyclone asymmetry concerning the height of the thermal and the dynamical tropopause, J. Atmos. Sci., 58, 26-37, 2001.

WMO: Atmospheric Ozone: 1985, Global Ozone Research and Monitoring Project, Report No. 16, World Meteorological Organization, 1986.

WMO: Scientific assessment of ozone depletion: 2002, Global Ozone Research and Monitoring Project, Report No. 47, World Meteorological Organization, 2003.

Zahn, A., Brenninkmeijer, C. A. M., van Velthoven, P. F. J.: Passenger aircraft project CARIBIC 1997-2002, Part II: the ventilation of the lowermost stratosphere, Atmos. Chem. Phys. Discuss., 4, 1119-1150, 2004, SRef-ID: 1680-7375/acpd/2004-4-1119.

Zierl, B. and Wirth, V.: The role of radiation for stratospheretroposphere exchange in an upper tropospheric anticyclone, J. Geophys. Res., 102, 23 883-23 894, 1997. 